\title{
EXPERIMENTAL PERFORMANCE EVALUATION OF A SOLAR-ASSISTED HEAT PUMP DRIVEN BY PV/T PANELS IN REAL AMBIENT CONDITIONS
}

\author{
Riccardo Simonetti, Luca Molinaroli and Giampaolo Manzolini \\ Department of Energy, Politecnico di Milano, Via Lambruschini 4, 20156 Milano, (Italy)
}

\begin{abstract}
Summary
This work summarizes the results of an experimental campaign carried out to access the performance of a solar-assisted heat pump combining a water-to-water heat pump and hybrid photovoltaic thermal panels. This concept improves the performance of the heat pump, due to water temperature higher than the ambient one, and the electrical efficiencies of the PV/T modules, thanks to cooling effect. The experimental campaign was conducted in an outdoor laboratory in real ambient conditions to evaluate the performance of the whole system demonstrating also the system robustness and reliability. Results show a high coefficient of performance, higher than the one of a standard air-source heat pump in the majority of the experimentations, with values up to 5 with a condenser inlet temperature equal to $30{ }^{\circ} \mathrm{C}$. From the solar panels point of view, very high efficiencies are achieved when the coolant fluid temperature is near the ambient temperature.
\end{abstract}

Keywords: Photovoltaic Thermal modules, Solar Assisted Heat Pumps.

\section{Introduction}

Photovoltaic thermal (PV/T) modules combine thermal and electricity production. The main drawback of this technology is the low thermal efficiency because of the high thermal losses (Aste et al., 2014; Zondag et al., 2003). An option to exploit the PV/T potentiality without increasing the module complexity consists of their integration with a heat pump (HP) leading to the so-called solar-assisted heat pump (SAHP) concept: the heat recovered by thermal or PV/T modules supplies the heat for the HP evaporator (Ji et al., 2008). A detailed study of this system was conducted by Nuntaphan et al. (2009) that experimentally analyzed the performance of an indirect SAHP (I-SAHP) coupled with flat solar collectors. Results demonstrated higher system efficiency with respect to traditional configurations (air/water HP or thermal panels) with a gain that reaches $40 \%$. Liu et al. (2014) investigated a system with a SAHP and vacuum solar collectors for residential use. An experimental set-up was used to validate a model built in TRNSYS. The study showed that, considering a system designed for a solar fraction of $20 \%$, about $66 \%$ of the thermal load can be covered in the worst month and it is possible to reduce the energy consumption by $55 \%$ with respect to a traditional layout with a boiler. Calise et al. (2016) studied the performance of a three-generation system composed by I-SAHP integrating $\mathrm{PV} / \mathrm{T}$ solar modules for heating/cooling loads in a residential application. The model, developed in TRNSYS, showed that the system can cover the entire thermal load and the average performance is higher than a standard $\mathrm{HP}$ by $30 \%$. Moreover, the I-SAHP configuration fixes the PV/T low stagnation temperature issue as the PV/T operating temperature can be close to the ambient one (Simonetti et al., 2018). Finally, the PV power output increases with respect to conventional PV module because of the PV cell cooling effect (Migliorini et al., 2017). All these results confirmed the good performance of the I-SAHP system, but pointed out its strong dependency from the environmental conditions, especially from solar radiation. In fact, a previous study of an I-SAHP was performed with a numerical model, confirming the potentialities of this technology but also pointing out the performance problems during cloudy days as well as during the night (Simonetti et al., 2017).

In this work, an experimental campaign was conducted to evaluate the behavior and the performance of an ISAHP system under real ambient conditions, demonstrating the feasibility of the concept. An analysis of the PV/T panels performance was also carried out to point out the benefits of the coupling of the two technologies.

The paper is structured as follow. Section 2 describes the experimental set-up. Section 3 presents the SAHP components, the experimental apparatus and the key performance parameters used in the analysis. Section 4 outline the filtering process and the uncertainty analysis. In Section 5, results are presented and discussed. Finally, Section 6 draws the conclusions of the work pointing out future research activities. 


\section{Experimental Facility}

The experimental setup is located in the North of Italy, at SolarTech laboratory on the roof of the Department of Energy of Politecnico di Milano, whose geographical coordinates are latitude 45 $30^{\prime} 10.588^{\prime \prime} \mathrm{N}$ and longitude $9^{\circ} 9^{\prime} 23.677^{\prime \prime} \mathrm{E}$. The experimental measurements are performed under real operating conditions using a meteorological station to monitor environmental conditions. PV/T panels are tilted $27^{\circ}$ and oriented $-3^{\circ}$ respect with the South direction (positive clockwise). Tests were carried out in the period from the $25^{\text {th }}$ of January to the $29^{\text {th }}$ of March 2019 ( 38 days of collected measurements) with ambient temperature between 5.3 ${ }^{\circ} \mathrm{C}$ and $24.5{ }^{\circ} \mathrm{C}$ and solar irradiance on horizontal plane between $127.4 \mathrm{~W} / \mathrm{m}^{2}$ and $1^{\prime} 097.5 \mathrm{~W} / \mathrm{m}^{2}$.

The experimental set-up used in the present work is an outdoor laboratory whose layout is shown in Figure 1.

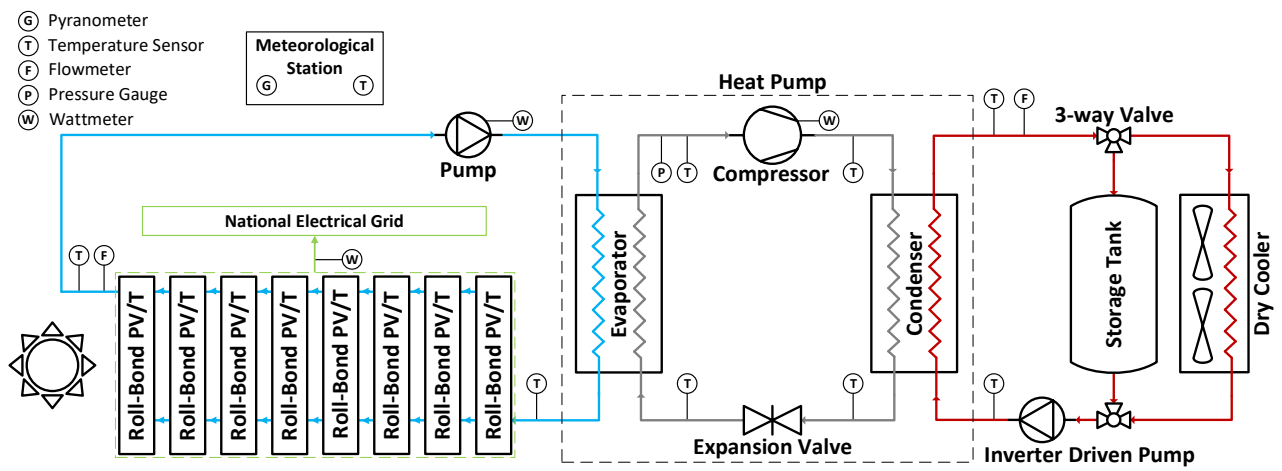

Figure 1 - Schematic of the experimental facility

In a cold water loop (blue line), a water-ethylene glycol mixture (30\%) flows through eight roll-bond PV/T collectors and is then transferred to the HP evaporator. The heat provided by the PV/T field acts as the low temperature heat source of the HP and the temperature achieved in the cold water loop may be even lower than the ambient one, increasing both the electric and the thermal efficiency of the PV/T modules. In the hot water loop (red line), the water is heated inside the condenser of the HP and sent to a hot storage tank. After that, thanks to a three-ways valve, the fluid could directly return to the inlet of the condenser or pass through a dry cooler for temperature control purpose. Indeed, the fans of this component are automatically controlled to keep the water temperature at HP condenser inlet constant to evaluate the performance of the SAHP system only as a function of the environmental conditions (solar irradiance and ambient temperature) since these influences most the behavior of PV/T panels.

As it is possible to see from the layout, temperatures were measured at the inlet and at the outlet of the PV/T solar field and of the condenser, even if those measurements were provided by the internal measurement system of the HP. In the same way, the evaporating pressure at the outlet of the evaporator and the superheated vapor temperature at the compressor outlet were obtained. The volumetric flow rates in the cold and hot loops were measured using vortex-based instruments. A wattmeter was used to measure the consumptions of the SAHP (compressor and circulating pump in the cold loop). About PV/T modules, the power generated is directly measured by the inverter which connects the modules to the grid. A meteorological station measured the solar irradiance on the tilted surface of the PV/T panels and the ambient temperature.

Finally, the first law energy balance was used to evaluate the accuracy of the measurements and to identify eventual thermal losses inside the HP cycle. Eq. 1 shows the considered terms, pointing out the parameter $\Delta \dot{E}$, which represents the error of the non-closure of the energy balance.

$\Delta \dot{E}=\dot{Q}_{c o n d}-\dot{Q}_{p v t}-\alpha_{c o m p} \cdot \dot{W}_{c o m p}-\dot{W}_{\text {pump }}$

where $\alpha_{\text {comp }}$ represents the part of the power consumed by the system components that enters into the HP cycle (the remaining part is lost) and $\eta_{\text {pump }}$ is the hydraulic efficiency of the pump. The heat produced in the cold loop $\left(\dot{Q}_{p v t}\right)$ was evaluated at the PV/T field side instead of the evaporator side because the instrument present inside the HP installed by the manufacturer had lower accuracy and reliability. Their measurements were anyway used to identify issues or errors. The consumption and efficiency of the circulating pump was calculated from a correlation obtained from the manufacturer data, as a function of the volumetric flow rate and the temperature of the fluid. 
In order to investigate more completely the behavior of this system, three different water temperatures at the condenser inlet were assumed, using the previously described temperature controlling system. The temperature selected are $30^{\circ} \mathrm{C}, 40^{\circ} \mathrm{C}$ and $50{ }^{\circ} \mathrm{C}$ respectively.

Detailed data of the instruments are reported in Table 1. The abbreviation RV stands for Reading Value and FS stands for Full Scale.

Table 1 - Technical informations of the measurement instruments

\begin{tabular}{lccc}
\hline Instrument & Model & Range & Uncertainty \\
\hline RTD & Pt 100 & $-50^{\circ} \mathrm{C}-250^{\circ} \mathrm{C}$ & $1 / 10 \mathrm{DIN}$ \\
Flowmeter & Huba-Control -210 & $0.91 / \mathrm{min}-15 \mathrm{l} / \mathrm{min}$ & $\pm 1 \% \mathrm{FS}$ \\
Wattmeter & CEWE - DPT221-401 & $<1100 \mathrm{~W}$ & $\pm 1 \% \mathrm{RV}$ \\
Power meter (Inverter) & SolarEdge & $<3 \mathrm{~kW}$ & $\pm 1 \% \mathrm{RV}$ \\
Pyranometer & LSI - DPA 252 & $<2000 \mathrm{~W} / \mathrm{m}^{2}$ & $<2 \% \mathrm{RV}$ \\
Thermohygrometer & LSI - DMA 875 & $-30^{\circ} \mathrm{C}-70^{\circ} \mathrm{C}$ & $1 / 3 \mathrm{DIN}$ \\
\hline
\end{tabular}

\section{SAHP Components and KPIs}

The system is composed by eight commercial PV/T panels and a commercial water-to-water HP. Each PV/T collector provided by Eclipse company (Eclipse, 2015) consists of a commercial PV modules (250 W peak power) with multi-silicon solar cells and a roll-bond heat exchanger attached to the back,. Each module is connected to a MPPT (Maximum Power Point Tracker) device and all of them are connected to a single inverter. This configuration allowed to maximize the performance of each module and easily collect the electrical data of the entire solar field. The HP is a water-to-water machine provided by Hidros company, with a nominal heating capacity equal to $3.4 \mathrm{~kW}$ at $45{ }^{\circ} \mathrm{C}$ of condenser leaving water temperature with a corresponding COP equal to 4.1. Figure 2 shows the details of the HP components, the front and back of PV/T modules.

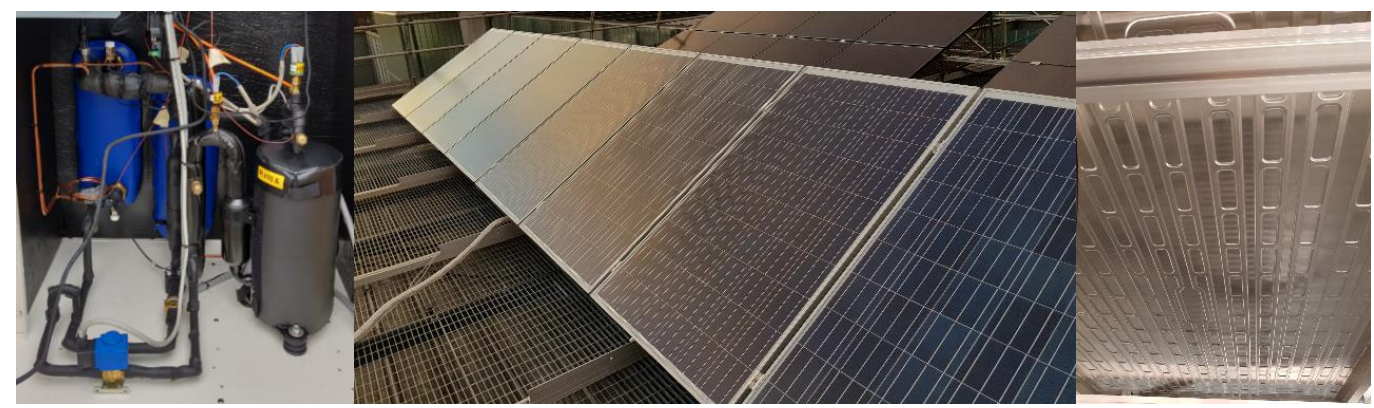

Figure 2 - From left to right: inside of the heat pump, front and back of PV/T modules

Table 2 summarizes the technical characteristics of the PV/T modules taken from the manufacturer datasheet. Performance is referred to the STC (Standard Test Conditions).

Table 2 - Technical characteristic of PV/T Eclipse modules

\begin{tabular}{lr}
\hline Electrical Power Output & $250 \mathrm{~W}$ \\
Electrical Efficiency & $15.1 \%$ \\
Thermal Power Output & 1 '040W \\
Zero-Loss Efficiency & $45.2 \%$ \\
Thermal Losses Coefficient & $1.65 \mathrm{~W} /\left(\mathrm{m}^{2} \mathrm{~K}\right)$ \\
Total Area & $1.66 \mathrm{~m}^{2}$ \\
\hline
\end{tabular}


The objective of the experimentation is to evaluate the performance of the I-SAHP system in different environmental and working conditions. Therefore, some Key Performance Indicators (KPIs) are introduced to assess the system performance. Firstly the Coefficient of Performance (COP) was evaluated as follow:

COP $=\frac{\dot{Q}_{\text {out }}}{\dot{W}_{\text {in }}}=\frac{\dot{V}_{\text {cond }} \cdot \rho \cdot c \cdot\left(T_{\text {cond }, \text { out }}-T_{\text {cond }, \text { in }}\right)}{\dot{W}_{\text {consumptions }}}=\frac{\dot{V}_{\text {cond }} \cdot \rho \cdot c \cdot\left(T_{\text {cond }, \text { out }}-T_{\text {cond }, \text { in }}\right)}{\dot{W}_{\text {comp }}+\dot{W}_{\text {pump }}}$

where $\dot{W}_{\text {consumptions }}$ is the sum of the electrical consumptions of the system. In addition to the compressor consumption $\dot{W}_{\text {comp }}$, the circulating pump consumption $\dot{W}_{\text {pump }}$ in the evaporator loop, which is directly controlled by the HP, is added.

Moreover, considering the performance of PV/T panels, electrical and thermal efficiencies have to be evaluated. The following equations show how these performance parameters are calculated:

$\eta_{\text {el }}=\frac{\dot{W}_{\text {out }}}{\dot{Q}_{\text {in }}}=\frac{\dot{W}_{\text {panel }}}{G_{T} \cdot A_{\text {panel }}}$

$\eta_{\text {th }}=\frac{\dot{Q}_{\text {out }}}{\dot{Q}_{\text {in }}}=\frac{\dot{V}_{\text {panel }} \cdot \rho \cdot c \cdot\left(T_{\text {panel }, o u t}-T_{\text {panel,in }}\right)}{G_{T} \cdot A_{\text {panel }}}$

where $\mathrm{G}_{\mathrm{T}}$ is the solar irradiance on the panels aperture area. PV/T modules efficiency can be described through the following equation typically adopted for covered flat plate collectors:

$\eta_{t h}=\eta_{\text {opt }}+a_{1} \cdot T_{R} \quad$ where $\quad T_{R}=\frac{\left(T_{\text {panel }, \text { out }}+T_{\text {panel,in }}\right) / 2-T_{\text {amb }}}{G_{T}}$

where $\eta_{\text {opt }}$ is the zero-loss efficiency, $a_{1}$ the thermal losses coefficient and $T_{R}$ is the reduced temperature. This simplified modelization can be adopted considering the very low wind speed presents during the experimentation period and also because the methodology was already verified in a previous work (Simonetti et al., 2018).

\section{Filtering Process and Uncertainty Analysis}

To improve the accuracy of the measurements for the considered system, data filtering is required to prevent the inclusion of outliers and transient phenomena as consequence of the variation of the environmental conditions the outdoor experimental facility experiences. The first step consists of selecting days with suitable weather conditions meaning high and constant solar radiation and negligible wind. All the measured data are imported with a 1 second timestep in MATLAB $®$ where one-minute average value is calculated to smooth the variability. Then, steady state conditions of the system are ensured by applying some filtering criterion: each criteria must be verified, meaning that if only one of the filter fails for a certain minute, the whole dataset for that minute is discarded.

The set of variables and filters adopted in the process is summarized in Table 3.

Table 3 - Variable used for filtering and thresholds

\begin{tabular}{lr}
\hline Flow Rate - Standard Deviation & $\sigma(\dot{V})<0.04 l / \mathrm{min}$ \\
$\mathrm{T}_{\text {in }} / \mathrm{T}_{\text {out }}-$ Variation between two minutes & $\Delta T<0.2^{\circ} \mathrm{C}$ \\
$\mathrm{T}_{\text {in }} / \mathrm{T}_{\text {out }}$ Condenser - Standard Deviation & $\sigma(T)<0.1^{\circ} \mathrm{C}$ \\
$\mathrm{T}_{\text {in }} / \mathrm{T}_{\text {out }}$ Evaporator - Standard Deviation & $\sigma(T)<0.05^{\circ} \mathrm{C}$ \\
Power Consumption - Standard Deviation & $\sigma(\dot{W})<5 W$ \\
Solar Irradiance - Standard Deviation & $\sigma(G)_{\%}<1 \%$ \\
$\mathrm{~T}_{\text {in }}$ Condenser - Difference respect to a target & $T_{\text {in }}-T_{\text {target }}<0.5^{\circ} \mathrm{C}$ \\
\hline
\end{tabular}


The values measured every second are averaged in a window of one minute, hence an uncertainty of type A is present. The sample is not large enough $(\mathrm{N}=60)$, thus it is necessary to adopt the t-student distribution to predict the confidence interval of the measured data. To evaluate the t-value, the degree of freedom (number of sample - 1) and the confidence level are required. For 59 degree of freedom and a $95 \%$ of confidence level, the t-value corresponds to 2.00 and uncertainty of type A can be calculated as follow:

$U_{A}\left(x_{i}\right)=t_{0.025} \cdot \frac{\sigma\left(x_{i}\right)}{\sqrt{N}}$

The uncertainties of quantities measured (uncertainty of type B) directly are evaluated referring to technical datasheets, whose main features are summarized in Table 1 . The uncertainty of the temperature measurements with the thermoresistance follows the regulation of EN 60751 and the formula is showed in the following equation:

$U_{B}(T)=D I N \cdot(0.3+0.005 \cdot T) \quad$ with $\mathrm{T}$ in ${ }^{\circ} \mathrm{C}$

In order to estimate the uncertainty of indirect quantities, the propagation theory is applied: considering $\mathrm{y}$ as a generic quantity depending on the $M$ samples of the direct quantities, calculated as $y=y\left(x_{1}, x_{2}, \ldots, x_{j}, x_{M}\right)$, its absolute uncertainty is computed with the equation:

$U(y)=\sqrt{\sum_{j=1}^{M}\left(\frac{\partial f}{\partial x}\right)^{2} \cdot U\left(x_{j}\right)^{2}}$

Following equations show the relative uncertainty $\mathrm{U}_{\%}$, evaluated as the ratio between the uncertainty and the mean value of the variable that the uncertainty is referred to, of a general thermal power produced and of the efficiencies of a PV/T module.

$U_{\%}\left(\dot{Q}_{i}\right)=\sqrt{U_{\%}\left(\dot{V}_{i}\right)^{2}+U_{\%}\left(\Delta T_{i}\right)^{2}}$

$U_{\%}\left(\eta_{t h, i}\right)=\sqrt{U_{\%}\left(\dot{Q}_{i}\right)^{2}+U_{\%}\left(G_{T, i}\right)^{2}}$

$U_{\%}\left(\eta_{e l, i}\right)=\sqrt{U_{\%}\left(\dot{W}_{i}\right)^{2}+U_{\%}\left(G_{T, i}\right)^{2}}$

where the relative uncertainty of the temperature difference is evaluable with the following expression:

$U_{\%}\left(\Delta T_{i}\right)=\frac{\sqrt{U\left(\Delta T_{\text {out }, i}\right)^{2}+U\left(\Delta T_{\text {in }, i}\right)^{2}}}{T_{\text {out }, i}-T_{\text {in }, i}}$

Finally, the relative uncertainty of the COP is calculated, and also the uncertainty of the first law energy balance, as expressed by:

$U_{\%}\left(C O P_{i}\right)=\sqrt{U_{\%}\left(\dot{Q}_{c o n d, i}\right)^{2}+U_{\%}\left(\dot{W}_{c o m p, i}\right)^{2}}$

$U\left(\Delta \dot{E}_{i}\right)=\sqrt{U\left(\dot{Q}_{\text {cond }, i}\right)^{2}+U\left(\dot{Q}_{p v t, i}\right)^{2}+\alpha_{c o m p}^{2} \cdot U\left(\dot{W}_{\text {comp }, i}\right)^{2}+U\left(\dot{W}_{\text {pump }, i}\right)^{2}}$

\section{Results}

The first important result of the experimental campaign is that the I-SAHP operated without any problems within the considered period. The start-up was done as soon as the solar source was available in the morning and the shutdown took place at the sunset or when the glycol temperature at evaporator inlet went under $0{ }^{\circ} \mathrm{C}$, due to a setting of the HP controller that didn't permit to go down. During operation, the system exhibited high robustness to the environmental changes (i.e. cloud passage), due to the high inertia of the PV/T system that reduced the amplitude of the solar irradiance variation. 
Figure 3 shows a typical sunny day during the experimental campaign. Temperatures around the HP, as well as the ambient temperature and the solar irradiance are reported. The condenser inlet temperature was set at 50 ${ }^{\circ} \mathrm{C}$. It is possible to see that the mean temperature of the fluid in the cold loop follows the solar irradiance trend and is always higher than the ambient temperature with temperature difference higher than $10{ }^{\circ} \mathrm{C}$.

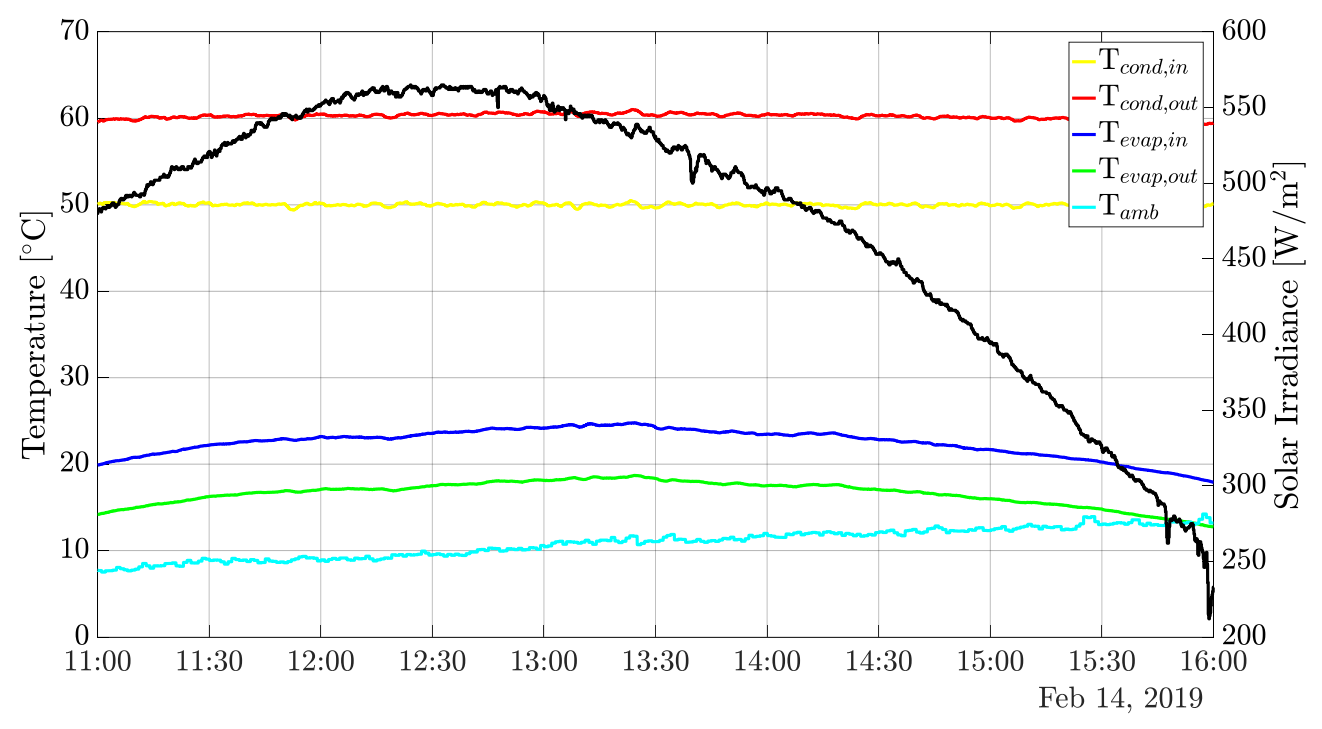

Figure 3 - Temperatures around the I-SAHP during a sunny day. Black line represents the solar irradiance

Figure 4 shows the COP as a function of the solar irradiance for three different temperatures at the inlet of the condenser. Values of COP around 5 are reached for high solar irradiance and condenser temperature of $30{ }^{\circ} \mathrm{C}$. In general, the higher the irradiance, the higher is the COP, while the condenser inlet temperature as expected penalizes the COP. It can be noted that the system has an acceptable COP also with very low solar irradiance, which is around at least 2.5 in the worst condition.

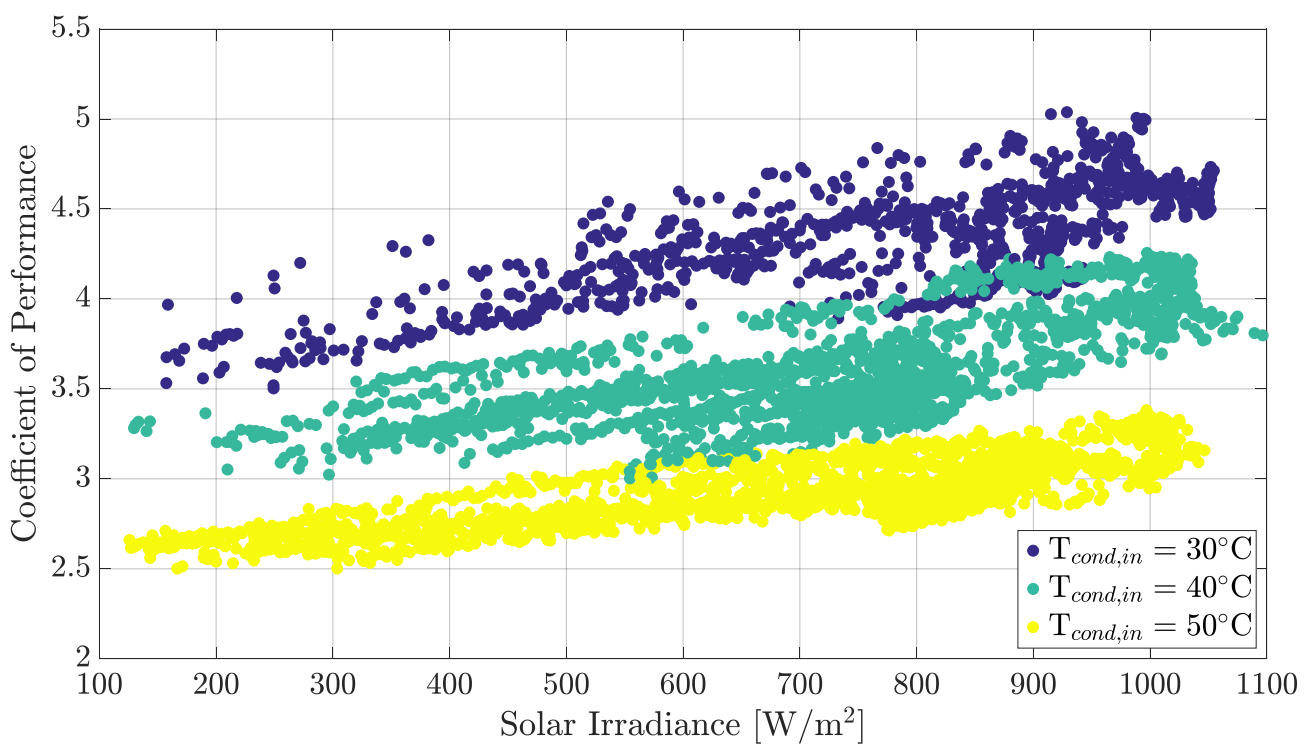

Figure 4 - Representation of COP as a function of solar irradiance for different condenser inlet temperatures

The impact of the ambient temperature on the COP is reported in Figure 5 pointing out that the COP increases with the ambient temperature, as expected. Moreover, the I-SAHP system has higher performance assuming the same ambient temperatures and condenser inlet temperatures with respect to an ASHP (solid lines) in the majority of the experimental conditions, confirming the potentialities of the concept. 


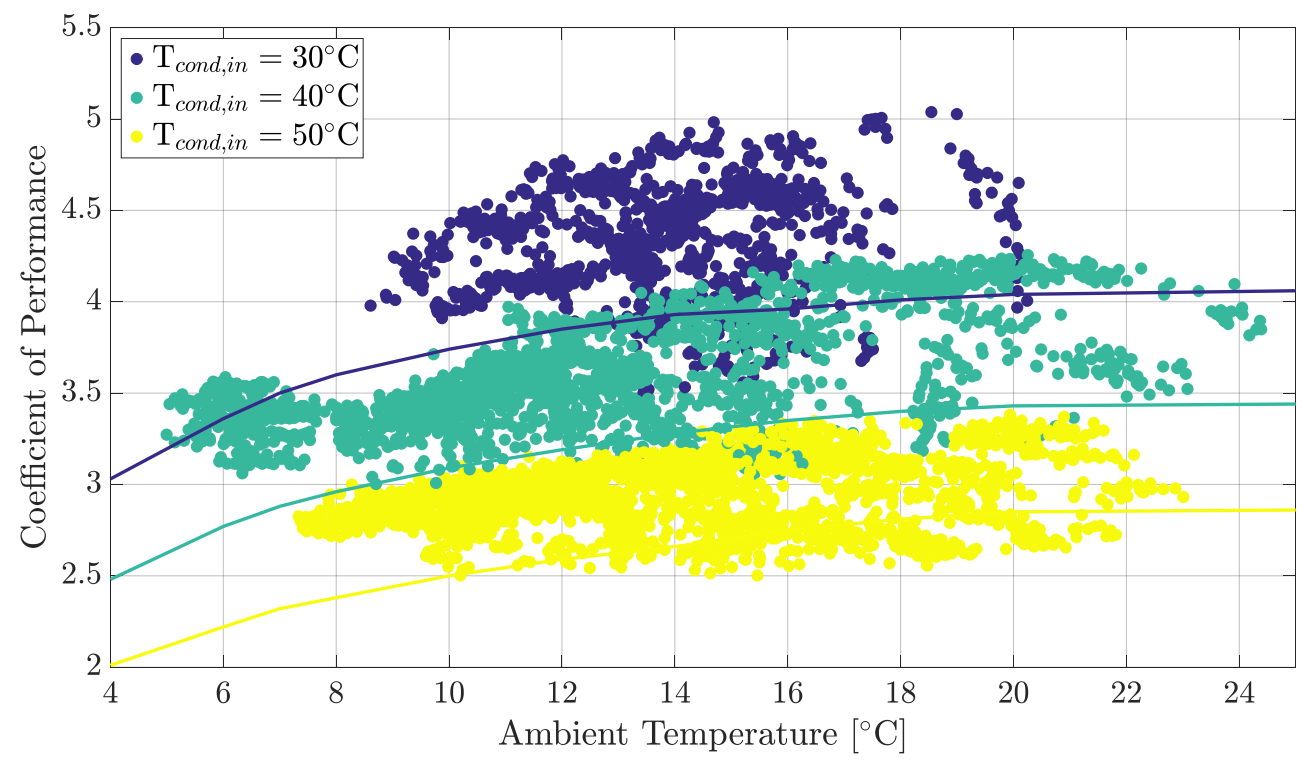

Figure 5 - Representation of COP as a function of ambient temperature for different condenser inlet temperatures. Solid lines represent the COP of a standard ASHP

Similarly, the comparison between the evaporator inlet temperature and the ambient one is reported in Figure 6. Most of the points are over the solid line indicating that the I-SAHP has a cold source temperature higher than the ASHP. For the considered system design condition, the threshold value for the parity of the performance for an ASHP and an I-SAHP is around $300 \mathrm{~W} / \mathrm{m}^{2}$. Moreover, the difference between the evaporator inlet temperature and the ambient one can reach $15^{\circ} \mathrm{C}$, which is a considerable result.

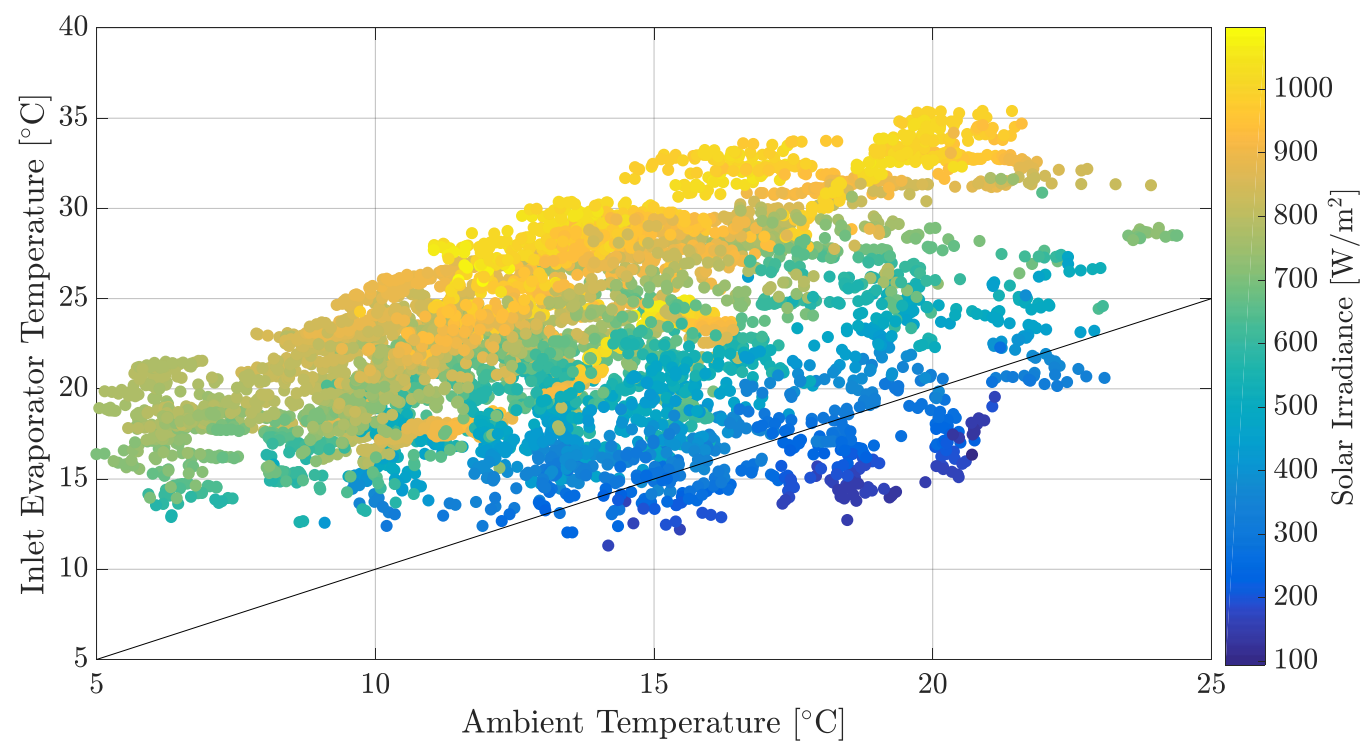

Figure 6 - Representation of the cold source temperature as a function of ambient temperature and solar irradiance

During the analysis of electrical performance of PV/T panels in this experimental campaign a problem was found, related to the inverter monitoring. Data were collected only from the 15th of March to the end of experimentation. Furthermore, the available timestep for data collection was 15 minutes, too high to accurately characterize the electrical behavior of the PV/T panels. Taking into consideration these limitations, Figure 7 shows the electrical ratio between the electricity production of the PV/T panels and the consumptions of the HP system as a function of solar irradiance and the condenser inlet temperature. It is possible to see that most of the points have a ratio higher than 1 . The self-consumption condition where reached with a solar irradiance from $500 \mathrm{~W} / \mathrm{m}^{2}$ to $650 \mathrm{~W} / \mathrm{m}^{2}$ for the three considered temperatures at the inlet of the condenser, from the lowest to the highest respectively. 


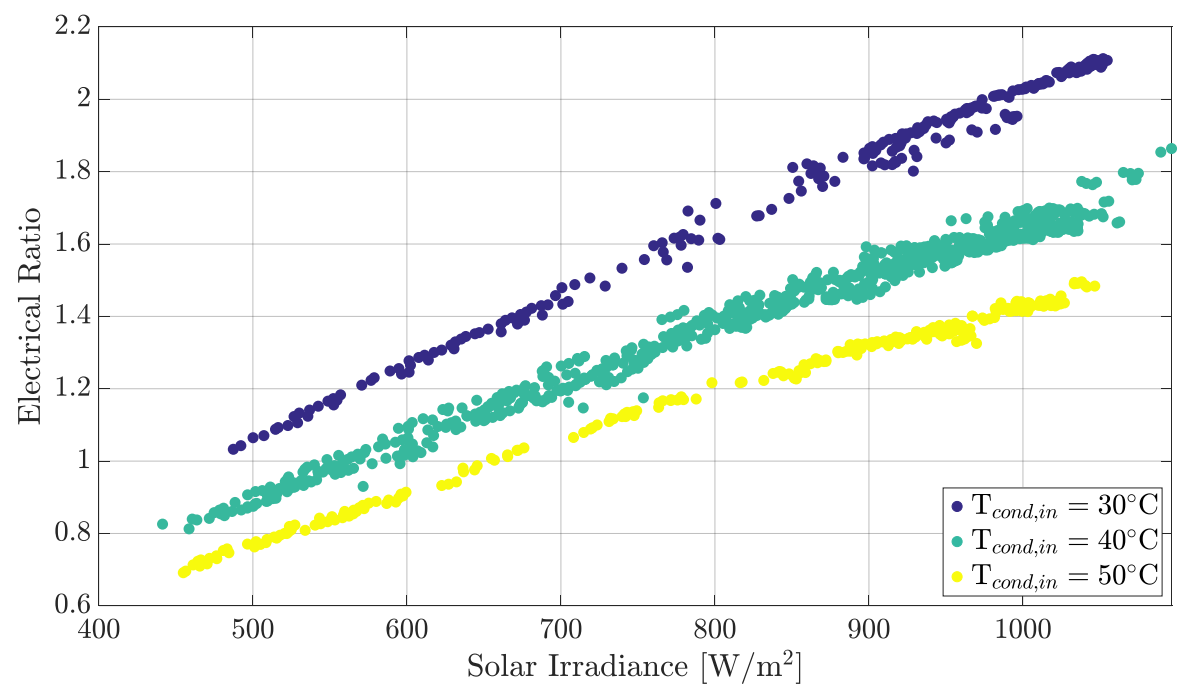

Figure 7 - Representation of the electrical ratio between PV/T production and SAHP system consumptions as a function of ambient temperature and solar irradiance

Moving to the PV/T panels, Figure 8 presents the thermal efficiency as a function of the reduced temperature. As it is possible to see, a very low reduced temperature can be reached, when the PV/T modules temperature is below the ambient one. In these conditions the thermal efficiency can be as high as 2. Moreover, all the filtered points present a linear trend confirming the feasibility of the method to determine the characteristic curve of PV/T under real environmental conditions as also discussed in a previous work (Simonetti et al., 2018). The linear regression was applied, and the $\mathrm{R}^{2}$ parameter displays the good application of the method, with a value higher than 0.85 . The two parameters obtained from the regression, $\eta_{\text {opt }}$ and $a_{1}$, are 0.442 and $16.57 \mathrm{~W} / \mathrm{m}^{2} \mathrm{~K}$ respectively. Comparing these results to the parameters provided by the manufacturer present in Table 2, the zero-loss efficiency is quite similar to the one declared, but the thermal losses coefficient is one order of magnitude higher. This difference is probably related to a mistake in the datasheet, also because the coefficient $\mathrm{a}_{1}$ of another PV/T panel based on roll-bond technology previously tested in the laboratory (SoLink, 2018 ) is around $13.8 \mathrm{~W} / \mathrm{m}^{2} \mathrm{~K}$.

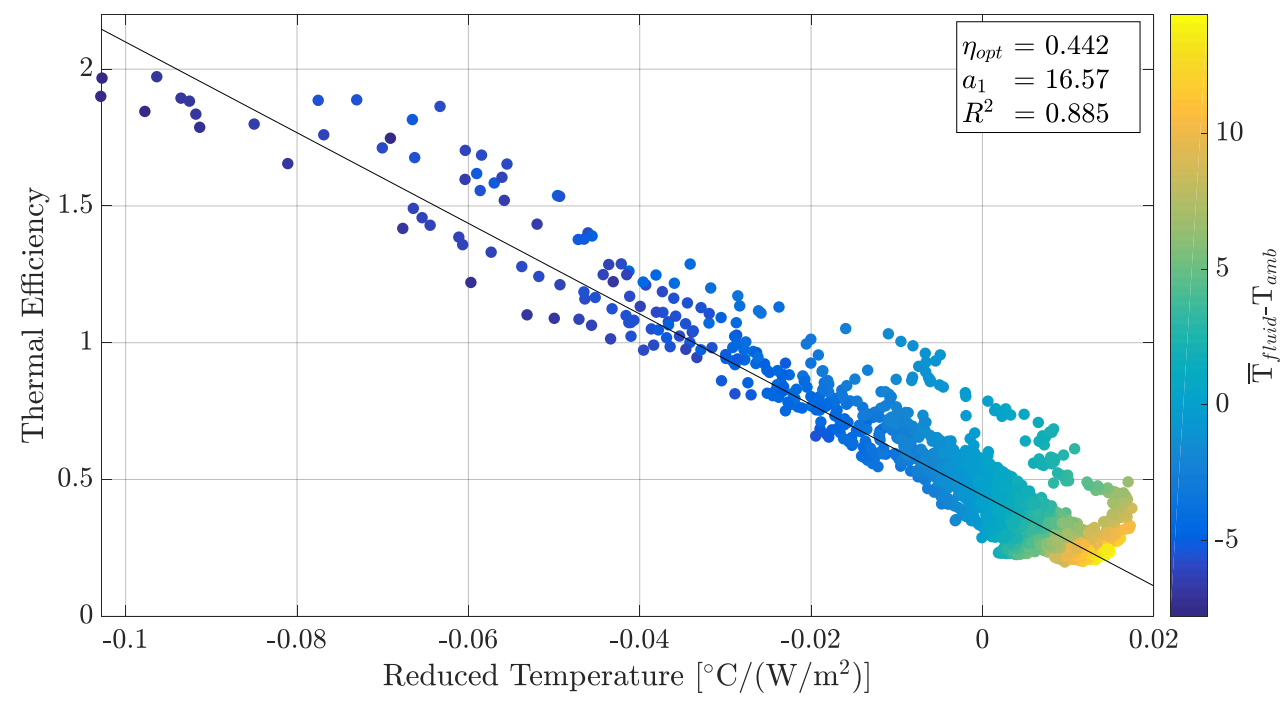

Figure 8 - Representation of the thermal efficiency of PV/T panels as a function of reduced temperature

The first law energy balance of the considered system is reported in Figure 9 through the parity plot between the power entering in the system (thermal power coming from the PV/T panels and electrical consumptions of the compressor and the cold loop circulating pump) and the useful effect (the thermal power produced by the condenser). The compressor is assumed to be isolated, therefore the value of the parameter $\alpha_{\text {comp }}$ was set as 1 (see Eq. 1). Three solid lines are also displayed: the one in the center represents the ideal closure of the balance, 
the two others consider the mean uncertainty of the measurements, creating a band where balance can be considered as closed.

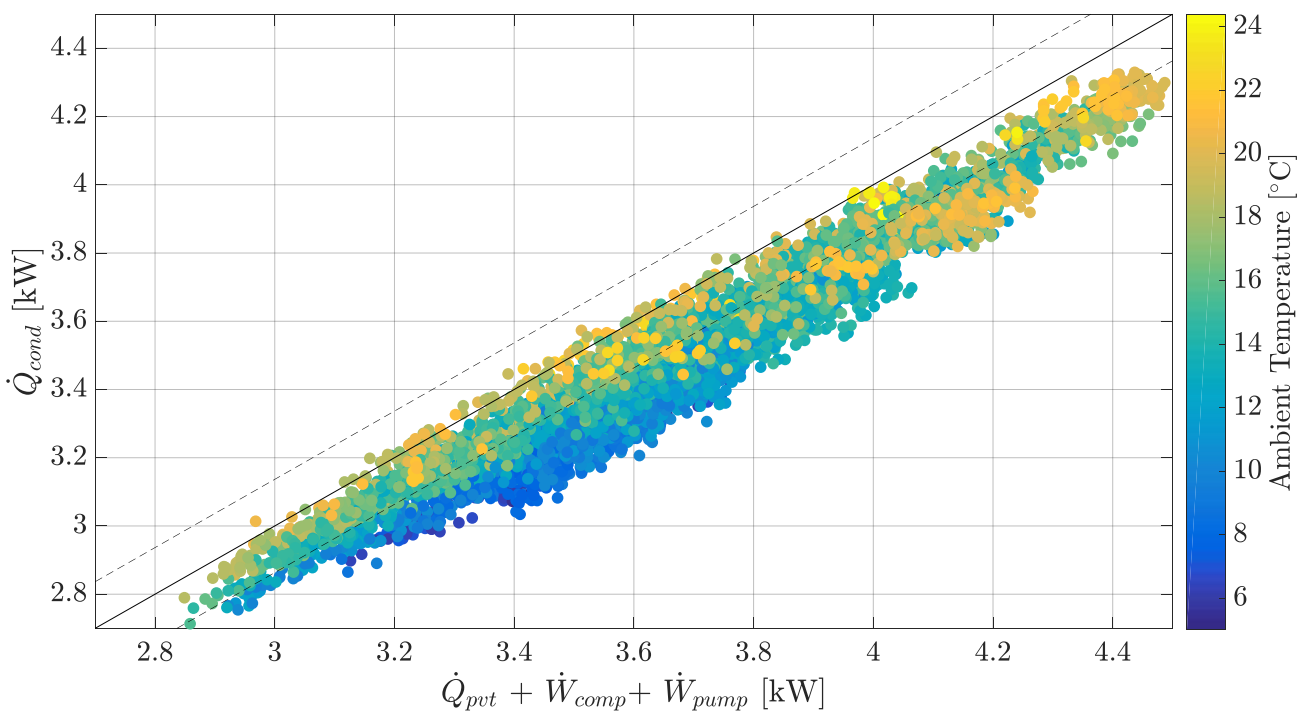

Figure 9 - Representation of the first law energy balance as a function of ambient temperature and solar irradiance

It is possible to see that only a little part of the experimental points is positioned inside the uncertainty band and the maximum error, considering the uncertainty band, of about $400 \mathrm{~W}$. Moreover, it is clearly visible a dependence on the ambient temperature or, more directly, on the thermal losses of the system, with higher balance error at lower ambient temperature.

However, the ambient temperature was not sufficiently low to justify high thermal losses, especially after the insulation procedure. Furthermore, negligible thermal losses can be identified in the cold loop, as shown in Figure 10 where the parity plot exhibits that all the experimental points stay inside the uncertainty band, also with very low ambient temperature. The evaluation of this physical incoherence will be an objective of futures works.

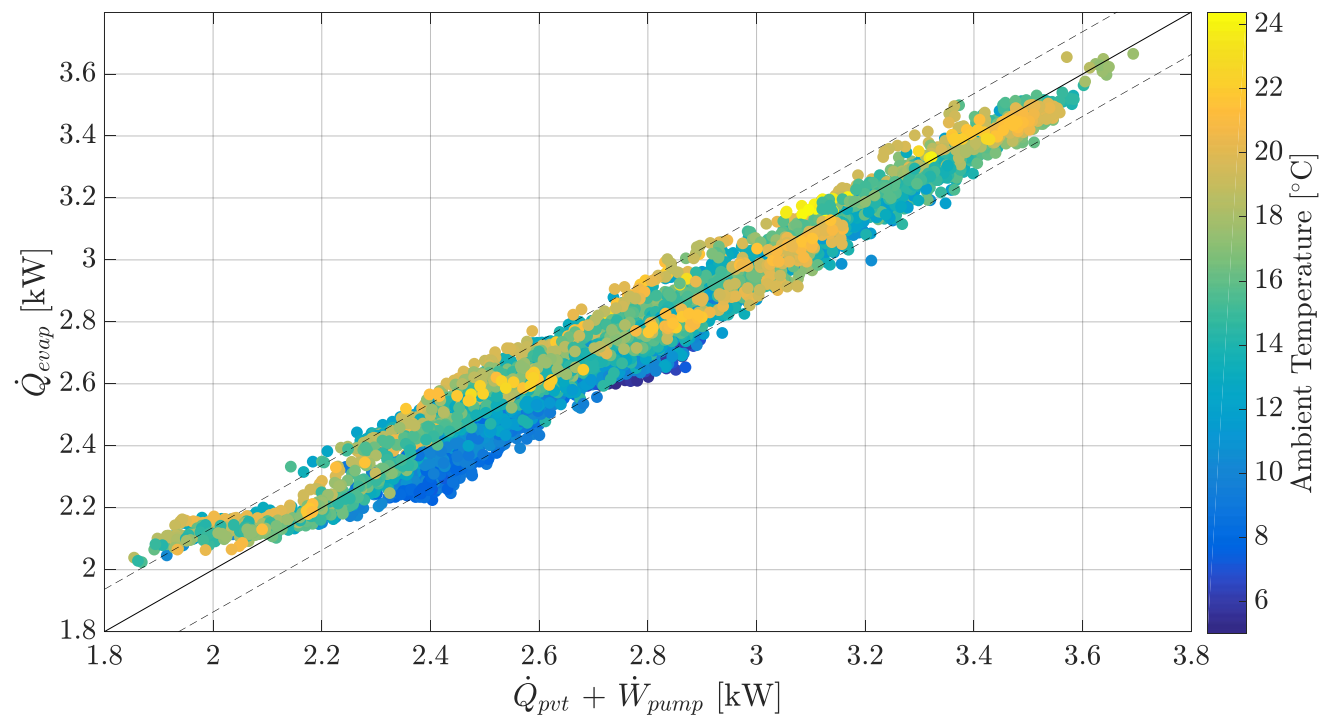

Figure 10 - Representation of the energy balance in the cold loop as a function of ambient temperature and solar irradiance

In Figure 11 the relative uncertainty of the COP as function of solar irradiance and volumetric flow rate in the hot loop is represented. The relative uncertainty is strongly affected by the flow rate and it slightly decreases with the solar irradiance as consequence of the higher HP cycle temperatures which reduces the relative uncertainty, according to Eq. 12. 


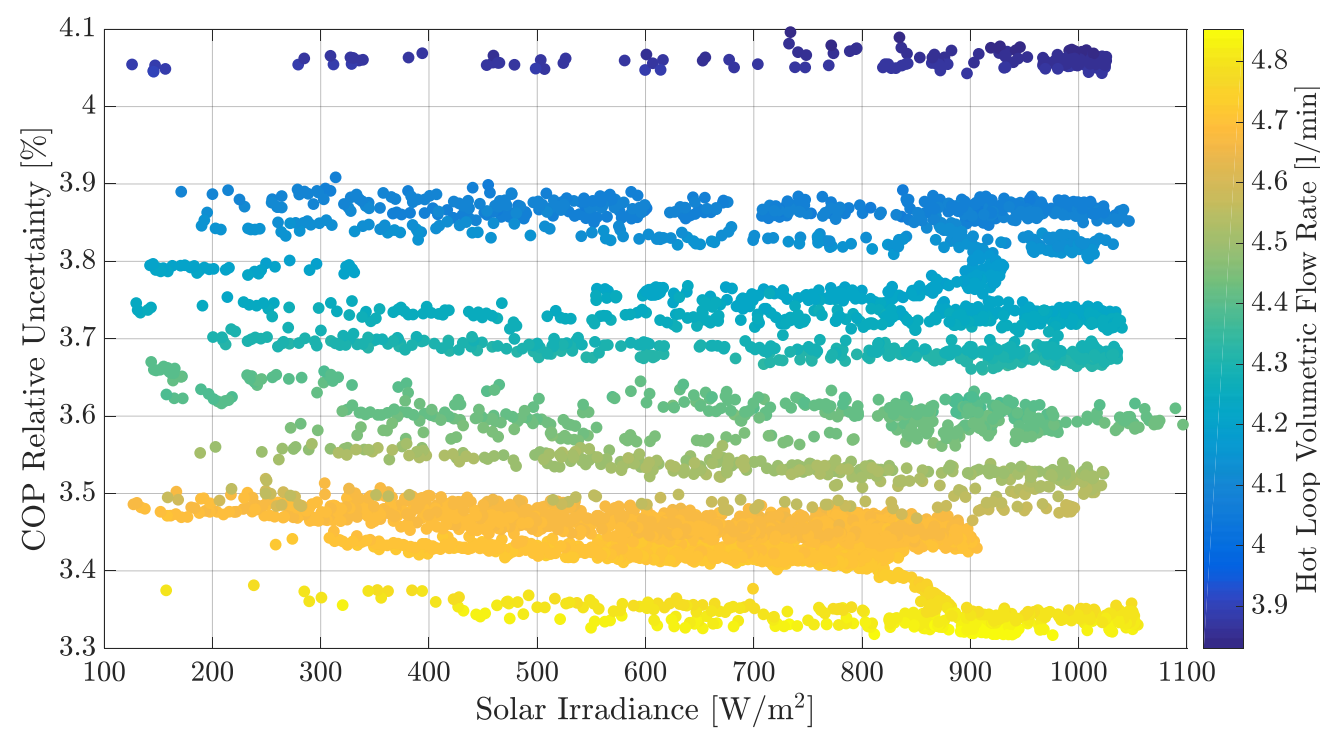

Figure 11 - Representation of the relative uncertainty of COP as a function of solar irradiance and hot loop flow rate

Finally, Table 4 summarizes the relative uncertainties, the minimum, maximum and average values of the thermal powers at the inlet and at the outlet of the HP, as well as of the COP, the electrical and thermal efficiency of PV/T panels and the first law energy balance. It is possible to see that the values are quite low, with mean values around $2.7 \%$ with limited variations between the minimum and the maximum. Electrical efficiency presents the lowest relative uncertainty, due to the fact that, considering Eq. 11, the electrical power measurement as well as the solar irradiance mensuration are very accurate. The highest uncertainty are referred to the energy balance, which is relative to the condenser thermal power.

Table 4 - Relative uncertainties of the main parameters of the experimental analysis

\begin{tabular}{lccc}
\hline & Mean Value & Min Value & Max Value \\
\hline$\dot{Q}_{p v t}$ & $2.50 \%$ & $2.33 \%$ & $2.70 \%$ \\
$\dot{Q}_{\text {cond }}$ & $3.42 \%$ & $3.16 \%$ & $3.97 \%$ \\
$\mathrm{COP}$ & $3.56 \%$ & $3.32 \%$ & $4.09 \%$ \\
$\eta_{\mathrm{th}}$ & $2.69 \%$ & $2.53 \%$ & $2.92 \%$ \\
$\eta_{\mathrm{el}}$ & $1.42 \%$ & $1.42 \%$ & $1.45 \%$ \\
$\Delta \dot{\mathrm{E}}$ & $3.92 \%$ & $3.73 \%$ & $4.38 \%$ \\
\hline
\end{tabular}

\section{Conclusions}

In this paper, an experimental campaign was conducted at the SolarTech ${ }^{\mathrm{LAB}}$, Politecnico di Milano, for 38 days between January and March of 2019, to evaluate the behavior and the performance of an I-SAHP system composed by a HP from the Hidros company and eight PV/T panels from Eclipse company. Experimentation was done in real ambient conditions with a controlled condenser inlet temperature so to identify the influence of the environmental conditions to the system performance. Moreover, condenser inlet temperature was varied, with value of $30{ }^{\circ} \mathrm{C}, 40{ }^{\circ} \mathrm{C}$ and $50{ }^{\circ} \mathrm{C}$ respectively, to increase the completeness of the analysis. The first important result is that the I-SAHP operated without any problems within the considered period with start-up and shut-down procedure depending on the evaporator inlet temperature (i.e. environmental conditions). Results have demonstrated the feasibility of the system, with high values of COP up to 5 with high solar irradiance. The comparison with an ASHP showed that in the most of the operating conditions, the I-SAHP system had better performance. In fact, the temperature of the cold source of the I-SAHP overcomes the ambient temperature for solar irradiance higher than $300 \mathrm{~W} / \mathrm{m}^{2}$. Also from the electrical part, the electricity produced by the PV/T modules covered the HP electric demand for solar irradiance values above $500 \mathrm{~W} / \mathrm{m}^{2}$. 
$\mathrm{PV} / \mathrm{T}$ performance were evaluated, showing that the parameters of the linear regression from the thermal efficiency, $\eta_{\text {opt }}$ and $\mathrm{a}_{1}$, were 0.442 and $16.57 \mathrm{~W} / \mathrm{m}^{2} \mathrm{~K}$ respectively. Thanks to the operating conditions below ambient temperature, the measured thermal efficiency of the PV/T module was even higher than 1 . Finally, the uncertainty analysis has outlined an accurate measurement apparatus, with a mean value of the relative uncertainty of the COP of $3.56 \%$.

\section{References}

Aste, N., Del Pero, C., Leonforte, F., 2014. Water flat plate PV-thermal collectors: A review. Sol. Energy 102, 98-115. https://doi.org/10.1016/j.solener.2014.01.025

Calise, F., Dentice d'Accadia, M., Figaj, R.D., Vanoli, L., 2016. A novel solar-assisted heat pump driven by photovoltaic/thermal collectors: Dynamic simulation and thermoeconomic optimization. Energy 95, 346-366. https://doi.org/10.1016/j.energy.2015.11.071

Eclipse, 2015. PV/T Eclipse [WWW Document]. URL http://www.eclipseitalia.com/images/download/TWINSUN/twinsun_HD_ita.pdf (accessed 1.28.19)

Ji, J., Pei, G., Chow, T.T., Liu, K., He, H., Lu, J., Han, C., 2008. Experimental study of photovoltaic solar assisted heat pump system. Sol. Energy 82, 43-52. https://doi.org/10.1016/j.solener.2007.04.006

Liu, H., Jiang, Y., Yao, Y., 2014. The field test and optimization of a solar assisted heat pump system for space heating in extremely cold area. Sustain. Cities Soc. 13, 97-104. https://doi.org/10.1016/j.scs.2014.05.002

Migliorini, L., Molinaroli, L., Simonetti, R., Manzolini, G., 2017. Development and experimental validation of a comprehensive thermoelectric dynamic model of photovoltaic modules. Sol. Energy 144, 489-501. https://doi.org/10.1016/j.solener.2017.01.045

Nuntaphan, A., Chansena, C., Kiatsiriroat, T., 2009. Performance analysis of solar water heater combined with heat pump using refrigerant mixture. Appl. Energy 86, 748-756. https://doi.org/10.1016/j.apenergy.2008.05.014

Simonetti, R., Manzolini, G., Molinaroli, L., 2017. Modeling of Solar Assisted Heat Pumps Combined with Photovoltaic Thermal Modules, in: Proceedings of SWC2017/SHC2017. International Solar Energy Society, Freiburg, Germany, pp. 1-12. https://doi.org/10.18086/swc.2017.33.08

Simonetti, R., Molinaroli, L., Manzolini, G., 2018. Experimental Performance Evaluation of PV/T Panels at Negative Reduced Temperatures, in: Proceedings of EuroSun 2018. International Solar Energy Society, Freiburg, Germany, pp. 1-10. https://doi.org/10.18086/eurosun2018.02.23

SoLink, 2018. PV/T SoLink [WWW Document]. URL https://www.solink.it/download/209/ (accessed 1.28.19).

Zondag, H.A., de Vries, D.W., van Helden, W.G.J., van Zolingen, R.J.C., van Steenhoven, A.A., 2003. The yield of different combined PV-thermal collector designs. Sol. Energy 74, 253-269. https://doi.org/10.1016/S0038-092X(03)00121-X 